\title{
JUSTIÇA DE TRANSIÇÃO NO BRASIL: O DIREITO À MEMÓRIA E À VERDADE E AS IMPLICAÇÕES JURÍDICAS DA LEI DE ANISTIA $^{1}$
}

TRANSITIONAL JUSTICE IN BRAZIL: THE RIGHT TO MEMORY AND TRUTH AND THE LEGAL IMPLICATIONS OF THE AMNESTY LAW

Maria Laura Silva de FIGUEIREDO²

Fábio Cantizani GOMES ${ }^{3}$

ISSUE DOI: $10.21207 / 2675-0104.2019 .936$

\section{RESUMO}

O intuito final do presente trabalho é averiguar as implicações jurídicas da Lei de Anistia, que deu início ao processo brasileiro de transição. Para tanto, utilizou-se da pesquisa bibliográfica, cuja contribuição para o desenvolvimento deste trabalho foi imprescindível, bem como a pesquisa documental. Dentre diversos temas, ao longo da análise é ressaltada a importância do julgamento da ADPF 153 e o papel do Supremo Tribunal Federal como legitimador de uma transição baseada no esquecimento. Com a pesquisa, foi possível concluir que os resquícios do autoritarismo do período da ditadura civil-militar brasileira ainda se fazem presentes no cotidiano da sociedade brasileira.

Palavras-chave: Justiça de transição. Anistia. Ditadura militar. Esquecimento.

\footnotetext{
${ }^{1} \mathrm{O}$ presente artigo sintetiza a monografia de conclusão da pesquisa, realizada para o Programa Interno de Bolsas de Iniciação Científica (PIBIC 2018-2019) da Faculdade de Direito de Franca (FDF), Franca/SP.

${ }^{2}$ Discente da Faculdade de Direito de Franca (FDF), Franca/SP. Bolsista do Programa Interno de Bolsas de Iniciação Científica (PIBIC 2018-2019).

${ }^{3}$ Doutorando em direito pela CEUB-ITE, Mestre e graduado pela UNESP - Franca/SP, professor de direito constitucional na Faculdade de Direito de Franca e na Universidade de Franca. Lattes: http://lattes.cnpq.br/7610232664441527. Contato: fabiocantizani@yahoo.com.br
} 


\section{ABSTRACT}

The final objective of the present work is to investigate the legal implications of the Amnesty Law, which initiated the brazilian transition process. To do so, it was used the bibliographic research, whose contribution to the development of this work was essential, as well as documentary research. Among several topics, the, the analysis highlights the importance of the "ADPF 153" judgment and the role of the Federal Supreme Court as legitimizing a transition based on forgetting. With the research it was also possible to conclude that the remnants of authoritarianism of the period of the Brazilian civilmilitary dictatorship are still present in the daily life of brazilian society.

Keywords: Transicional justice. Amnesty. Military dictatorship. Forgetting.

\section{INTRODUÇÃO}

Em diferentes períodos de sua história, o Brasil viveu sob a égide de governos autoritários. O último deles foi a ditadura civil-militar, que durou 21 anos. Em 31 de março de 1964, tropas do Exército ocuparam as ruas das principais cidades do país, destituindo João Goulart e implantando um longo de lamentável regime militar no Brasil, que foi marcado pela ruptura com a democracia, pela cassação de direitos políticos dos opositores e pela violação das liberdades individuais. Durante esse tempo, os cidadãos foram privados de diversos diretos devido a uma forte repressão e ferrenha censura, que produz efeitos até hoje.

A redemocratização não conseguiu, no entanto, apagar boa parte desse lamentável e doloroso legado, pois em 1979, o último presidente militar, João Batista Figueiredo, promulgou a Lei $\mathrm{n}^{\circ} 6.683$, conhecida como lei de anistia, que perdoou os crimes praticados durante a ditadura militar. A referida lei foi, inclusive, objeto de contestação na Corte Interamericana de Direitos Humanos e no Supremo Tribunal Federal.

Para se reconciliar com o passado, preparar o futuro e consolidar sua democracia, o país deu início a implementação da chamada justiça de transição, seguindo o exemplo de nações que também foram governadas por ditaduras. É por meio dela que se busca a responsabilização dos agentes que cometeram crimes, a reparação das vítimas e a garantia do direito à memória e à verdade, iniciativas necessárias para assegurar a não repetição das graves violações ocorridas no passado.

Portanto, uma visão jurídica acerca da influência da lei de anistia na viabilidade de uma efetiva e eficiente justiça de transição é mais que necessária: é devida. 
No primeiro capítulo deste trabalho, abordam-se os aspectos históricos sobre a ditadura civil-militar brasileira. O capítulo seguinte ocupa-se da análise dos principais mecanismos, conceitos e pilares referentes à justiça de transição. No terceiro e último capítulo, o trabalho cumpre com seu principal objetivo, que é analisar as implicações jurídicas da lei de anistia, e discorrer sobre os desafios da justiça de transição, demonstrando as consequências de sua ineficiência para a efetivação de uma verdadeira cidadania democrática.

Com a investigação científica realizada, pretende-se demonstrar que o Estado brasileiro ainda conta com resquícios autoritários em suas instituições. A pesquisa explica também a motivação da transição pactuada escolhida pelo país. A contribuição social da pesquisa se dá no sentido de que ela pode ser útil para os cidadãos na medida em que tem o condão de promover o acesso da população à informação.

A pesquisa bibliográfica, representada pelo levantamento de referências teóricas já analisadas e publicadas por meios escritos e eletrônicos, como livros e páginas de web sites, tem inegável contribuição para o desenvolvimento deste trabalho.

\section{ASPECTOS HISTÓRICOS DA DITADURA CIVIL- MILIUTAR BRASIELIRA}

A genuína compreensão da transição política brasileira requer, inicialmente, uma análise cuidadosa dos fatos que ocorreram no passado, especialmente durante o regime militar, período compreendido entre os anos de 1964 e 1985, uma vez que não se pode permitir que fases excepcionais como essa sejam entregues ao esquecimento de uma nação.

Ancorando-se nos dizeres de Pablo Dominguez Martinez, é possível perceber a importância da preservação dessa memória:

A superação do passado, o alheamento das abusividades, a intenção de "impunidade" constituem uma forte tendência, principalmente por aqueles que já foram participantes de governos ditatoriais e pretendem que a sociedade como um todo não inicie uma busca por punição e revide. ${ }^{4}$

\footnotetext{
${ }^{4}$ MARTINEZ, Pablo Dominguez. Direito ao Esquecimento: a proteção da memória individual na sociedade da informação. Rio de Janeiro: Lumem Juris, 2014. p. 70.
} 
Nesse sentido, examinar as raízes desse intervalo de tempo é fundamental para entender como a infiltração da ditadura em diversos setores da sociedade, tais como político, econômico, legislativo, educacional e social, contribuiu para torná-la um óbice à concretização do processo de transição.

Nas eleições de 1960, Jânio Quadros, candidato do Partido Trabalhista Nacional (PTN), apoiado pela União Democrática Nacional (UDN), venceu o pleito, renunciando ao cargo pouco tempo depois. Seguindo a ordem de sucessão presidencial, João Goulart deveria assumir o cargo. Porém, não foi o que aconteceu, pois sua posse só foi aceita após uma manobra no Congresso, que instituiu o parlamentarismo no país. A Constituição de 1946 foi, então, reformada, reduzindo os poderes do presidente e criando a figura do primeiro-ministro. Mesmo com poderes limitados, Jango aceitou a proposta.

Nas palavras de Elio Gaspari, João Goulart

[...] só assumira porque aceitara, depois de uma crise em que o país esteve perto da guerra civil, uma fórmula pela qual se fabricou um humilhante regime parlamentarista cuja existência residia em permitir que ocupasse a Presidência desde que não lhe fosse entregue o poder. ${ }^{5}$

Numa tentativa de reverter a situação, Jango mobilizou forças políticas para, em 1963, realizar um plebiscito para que a população pudesse decidir qual sistema de governo deveria ser adotado no país: presidencialismo ou parlamentarismo. Com o reestabelecimento do presidencialismo, Jango recuperou os poderes presidenciais em janeiro de 1963 e retomou, por pouco tempo, as rédeas da nação.

A desconfiança e instabilidade política, porém, cresciam cada vez mais até que, na madrugada do dia 31 de março, tropas do Exército ocuparam as principais ruas do país, destituindo Jango e instaurando um longo e doloroso regime militar, que iria transformar para sempre o país.

Com a ruptura do regime democrático, era preciso organizar o país, definir um projeto de governo que fosse além do combate à "ameaça comunista" e conciliar os interesses dos setores da sociedade civil que apoiaram o golpe.

No campo legislativo, os militares passaram a decretar Atos Institucionais (AI), utilizados para dar força de lei às suas ações, na tentativa de encaixar o golpe dentro de parâmetros legais.

\footnotetext{
${ }^{5}$ GASPARI, Elio. A ditadura envergonhada. 2. ed. São Paulo: Companhia das Letras, 2002. p. 48.
} 
Nota-se, com isso, que um traço marcante da ditadura militar brasileira foi a intensa preocupação em formar um arcabouço legal e jurídico que the garantisse respaldo e legitimidade.

Os atos institucionais, a Constituição de 1967, a Lei $\mathrm{n}^{\circ}$ 7.170/1983, conhecida como lei de segurança nacional e a Emenda Constitucional $n^{\circ} 1 / 69$ (EC N ${ }^{\circ} 1 / 69$ ), que promoveu profundas alterações no texto constitucional de 67 , foram os principais mecanismos legais para legitimar e legalizar o regime.

A violência arbitrária passou a fazer parte do cotidiano dos brasileiros. De um lado, o Estado, exorbitando o monopólio do uso da força e do outro, a resposta dos grupos de esquerda, com assaltos, sequestros de representantes de governos estrangeiros, expropriações e outros métodos

Torna-se importante recorrer, neste ponto, aos escritos de Sávia Cordeiro de Souza, que destaca um importante mecanismo de repressão utilizado pelo governo:

\begin{abstract}
No período de 1968 a 1974, a tortura se consolidou como a essência do aparato repressivo. Apesar de já estar presente desde o início do golpe, é durante o governo Médici que a identidade da ditadura se concretiza no uso sistematizado da tortura. Diante da sua ampla utilização, a tentativa do governo em omitir a existência de centros secretos de tortura não tinha mais sucesso. Várias organizações internacionais, religiosas e de direitos humanos passaram a coletar provas, a partir dos testemunhos de presos políticos e a trazer ao conhecimento da comunidade internacional a situação de violação de direitos humanos existente no país naquele período. ${ }^{6}$ (grifo nosso)
\end{abstract}

A tortura, além de ser desumana, é o meio mais inadequado para alcançar a verdade, pois, ao contrário do que se entendeu durante muito tempo no Brasil, não se revela um meio eficiente de forçar as pessoas a falarem a verdade, uma vez que é possível fazer uma pessoa admitir tudo quanto for sugerido pelo torturador devido ao sofrimento insuportável ao qual é submetia, além de ser o crime mais cruel e bárbaro contra a pessoa humana. $^{7}$

Em seus escritos, Norberto Bobbio, filósofo político, considera que o direito de não ser torturado é um direito absoluto da pessoa humana:

\footnotetext{
${ }^{6}$ SOUZA, Sávia Cordeiro de. A justiça de transição brasileira: Lei 6.683/79 e a luta contra uma política de esquecimento. 2012. Dissertação (Mestrado em Direito) - Faculdade de Direito, Pontifícia Universidade Católica, 2012. p. 68.

${ }^{7}$ ARQUEDIOCESE DE SÃO PAULO. Brasil: nunca mais. 15. ed. Petrópolis: Vozes, 1985. 312 p.
} 
Inicialmente cabe dizer que, entre os direitos humanos, como já se observou várias vezes, há direitos com estatutos muito diversos entre si. Há alguns que valem em qualquer situação e para todos os homens indistintamente: são os direitos acerca dos quais há exigência de não serem limitados nem diante de casos excepcionais, nem com relação a esta ou àquela categoria, mesmo restrita, de membros do gênero humano (é o caso, por exemplo, do direito de não ser escravizado e de não sofrer tortura). Esses direitos são privilegiados porque não são postos em concorrência com outros direitos, ainda que também fundamentais. ${ }^{8}$ (grifo nosso)

Em 1979, João Batsita Figueiredo, o quinto e último militar, assume a presidência do país, sendo o responsável por finalizar a abertura política. Seu governo é marcado por diversas transformações institucionais em consonância com o processo de abertura que estava sendo executado.

Após tantos anos de ditadura militar, os anseios democráticos corriam pelas veias dos brasileiros. Diversos movimentos sociais eclodiram, sendo o principal, em 1984, a campanha das Diretas Já, que pressionava pela aprovação da Emenda Dante de Oliveira, que reestabelecia as eleições diretas para presidente. A emenda, entretanto, não passou no Congresso. No dia 15 de janeiro de 1985, o Colégio Eleitoral elegeu Tancredo Neves que, na véspera da posse, foi hospitalizado devido a uma doença intestinal. Assim, em 21 de abril de 1985, José Sarney era empossado como primeiro presidente civil após 21 anos de ditadura militar, com a missão de instalar uma Assembleia Nacional Constituinte e reconduzir o país à normalidade democrática.

Com o fim da ditadura militar, inicia-se no país o processo de redemocratização. Os presidentes que se seguiram à ditadura tentaram resolver os problemas deixados por ela, principalmente na economia. No plano social, resquícios do autoritarismo militar podem ser percebidos até hoje, como irá ser apresentado nos próximos capítulos desta pesquisa.

\section{UM PROCESSO EM ABERTO: A JUSTIÇA DE TRANSIÇÃO NO BRASIL}

Após o fim da Primeira Guerra Mundial ocorreu a ascensão de regimes totalitários, tanto de direita, quanto de esquerda. Na Europa ocidental, o nazifascismo e, na Europa oriental, o comunismo. Dentro

\footnotetext{
${ }^{8}$ BOBBIO, Norberto. A Era dos Direitos. 9. ed. Tradução de Carlos Nelson Coutinho. Rio de Janeiro: Campus, 1992, p. 20.
} 
dessa conjuntura eclode, no ano de 1939, a Segunda Guerra Mundial, um conflito que envolveu nações de todos os continentes. Dois eram os grupos de combate: os países do Eixo, integrado por Alemanha, Itália e Japão, e os países Aliados, composto por França, Reino Unido, União das Repúblicas Socialistas Soviéticas e Estados Unidos da América.

Em 1945, as tropas Aliadas venceram o confronto, colocando fim à guerra e iniciando a fase inaugural da história moderna da justiça de transição. O período pós-guerra é um verdadeiro marco na trajetória do direito internacional. A barbárie e o totalitarismo dos regimes fascistas causaram monstruosas violações de direitos humanos e aboliram completamente o valor do ser humano. ${ }^{9}$ Assim, com o fim do conflito, o tema justiça de transição passou a receber cada vez mais atenção nas discussões sobre redemocratização, além de ter havido uma verdadeira consolidação do sistema internacional de proteção aos direitos humanos, que foi instrumentalizado com a criação de diversos órgãos e documentos internacionais.

Nesse sentido, foram criados tribunais de exceção, chamados de tribunais ad hoc, para apurar os fatos acontecidos durante a guerra, sendo os mais célebres o Tribunal de Nuremberg e o Tribunal de Tóquio que julgaram, respectivamente, oficiais alemães e japoneses pelos crimes praticados durante o conflito, mediante o estabelecimento de três categorias de crimes: crimes de guerra, crimes contra a paz e crimes contra a humanidade. Dessa forma, esses tribunais implementaram mecanismos que se tornaram verdadeiros marcos para a justiça transicional.

Justiça de transição é a denominação dada para um conjunto de mecanismos adotados por países egressos de regimes ditatoriais ou conflitos internos, para lidar com a herança de graves violações de direitos humanos. É por meio dela que se busca a responsabilização dos agentes que cometeram crimes, a reparação das vítimas e a garantia do direito à memória e à verdade, iniciativas necessárias para assegurar a não repetição das graves violações ocorridas no passado. Isso será feito por meio de vários instrumentos, gerando consequências jurídicas, políticas e sociais, com impactos que dependem de algumas variáveis, como as características do regime autoritário, o tipo de transição escolhida e a dinâmica internacional na qual o país está inserido.

Existe uma extensa variedade de mecanismos utilizados na execução da justiça de transição e também diversos objetivos. Contudo,

\footnotetext{
${ }^{9}$ PIOVESAN, Flávia. Direitos humanos e o direito constitucional internacional. 7. ed. São Paulo: Saraiva, 2006. pp. 115-116.
} 
alguns instrumentos se destacam mais na bibliografia sobre o tema, sendo: (1) A responsabilização e punição dos perpetradores que cometeram crimes contra a humanidade e violações de direitos. Trata-se da justiça criminal, que engloba julgamentos e anistias; (2) $\mathrm{O}$ acesso à informação: a busca pela verdade e o resgate à memória. No Brasil, destacam-se: a Lei de Anistia - Lei 6.683/79, a Lei dos Mortos e Desaparecidos Políticos - Lei 9.140/95 e a Comissão Especial sobre Mortos e Desaparecidos Políticos (CEMDP), a Medida Provisória 65, covertida na Lei 10.559/02 e a Comissão de Anistia, a ADPF 153 e a Lei de Acesso à Informação - Lei 12.527/11 e a Comissão Nacional da Verdade; (3) Reparação de danos cometidos à sociedade; (4) Reformas Institucionais, que consistem em organizar as instituições democráticas para que não volte mais a acontecer, implementando instrumentos para solidificar as instituições democráticas.

Para Paulo Sérgio Pinheiro, à época da Constituinte, a conciliação pelo alto foi a forma convencionada para se livrar do autoritarismo, entretanto ela não foi suficiente para promover uma transição substancialmente democrática, visto que não acolheu as lutas populares. ${ }^{10}$ Diante dessa problemática de anseios reprimidos, a consolidação do Estado Democrático de Direito pós-autoritarismo inevitavelmente lida com reflexos da insatisfação de grupos oprimidos, que serão abordados a seguir.

Após 21 anos de ditadura, a promulgação da Constituição Federal de 1988, conhecida como "Constituição Cidadã", devido aos grandes avanços sociais jacentes no bojo de seu texto, marcou a concretização do processo brasileiro de transição política, conduzindo definitivamente os civis de volta ao poder e colocando o país novamente nos trilhos da normalidade democrática. Assim, o que ocorreu foi uma transição política negociada, e não uma ruptura repentina.

Em relação à justiça de transição brasileira, esta pesquisa adota o posicionamento de Glenda Mezarobba, cientista política especialista em justiça de transição, que defende o argumento de que, no tocante ao caso brasileiro, trata-se de um processo inconcluso ${ }^{11}$ de transição, que se iniciou ainda dentro do regime militar, com a promulgação da Lei $n^{\circ} 6.683 / 79$,

\footnotetext{
${ }^{10}$ PINHEIRO, Paulo. Sérgio. A cidadania das classes populares, seus instrumentos de defesa e o processo constituinte. In: SADER, E. (Org). Constituinte e Democracia no Brasil hoje. 2. ed. São Paulo: Brasiliense, 1985. p. 55.

${ }^{11}$ MEZAROBBA, Glenda. 26 anos de anistia: um processo inconcluso. In: Novos Estudos, $\mathrm{n}^{\circ}$ 70, São Paulo, 2004. p. 19.
} 
responsável por conduzir o acerto de contas do Estado brasileiro com a sociedade civil organizada.

\section{AS IMPLICAÇÕES JURÍDICAS DA LEI DE ANISTIA}

Anistia, graça e indulto. Todos esses institutos são formas de extinção da punibilidade e estão previstos no artigo 107, II do Código Penal, que dispõe que "extingue-se a punibilidade pela anistia, graça ou indulto". ${ }^{12}$

Trazendo a análise para o campo do direito constitucional, cabe recorrer ao jurista Ruy Barbosa, simpatizante do instituto da anistia, segundo o qual esta seria um "véu de eterno esquecimento". ${ }^{13}$

Diante disso, pode-se afirmar que se trata de um instituto do direito penal material que interessa essencialmente ao direito constitucional por estar intimamente ligado à ideia de esquecimento.

Em 27 de junho de 1979, por iniciativa do então Presidente João Figueiredo, foi enviado ao Congresso Nacional o projeto de Lei $\mathrm{n}^{\circ} 14 \mathrm{de}$ 1979, referente à lei de anistia, que fora aprovado em 22 de gosto e sancionado no dia 28 do referido mês.

No caput do artigo primeiro, evidencia-se o prazo de alcance da lei, que vai de 02 de setembro de 1961 a 15 de agosto de 1979, sendo que inclui aqueles que cometeram crimes políticos ou conexos com estes e eleitorais, mas excluí do benefício da anistia os que foram condenados pela prática de crimes de terrorismo, assalto, sequestro e atentado pessoal, os chamados crimes de sangue.

Art. $1^{\circ}$ É concedida anistia a todos quantos, no período compreendido entre 02 de setembro de 1961 e 15 de agosto de 1979, cometeram crimes políticos ou conexo com estes, crimes eleitorais, aos que tiveram seus direitos políticos suspensos e aos servidores da Administração Direta e Indireta, de fundações vinculadas ao poder público, aos Servidores dos Poderes Legislativo e Judiciário, aos Militares e aos dirigentes e representantes sindicais, punidos com fundamento em Atos Institucionais e Complementares.

${ }^{12}$ BRASIL. Decreto-lei $\mathbf{n}^{\mathbf{o}} \mathbf{2 . 8 4 8}$, de 7 de dezembro de 1940. Código Penal. Disponível em: http://www.planalto.gov.br/ccivil_03/decreto-lei/del2848compilado.htm. Acesso em: 02 jul. 2019.

${ }^{13}$ BARBOSA, Ruy. Amnistia inversa: caso de teratologia jurídica. 2. ed. Rio de Janeiro: Typ. Do Jornal do Commercio, 1986. 
$\S 1^{\circ}$ - Consideram-se conexos, para efeito deste artigo, os crimes de qualquer natureza relacionados com crimes políticos ou praticados por motivação política.

$\S 2^{\circ}$ - Excetuam-se dos benefícios da anistia os que foram condenados pela prática de crimes de terrorismo, assalto, seqüestro e atentado pessoal. ${ }^{14}$ (grifo nosso)

Está presente aqui o ponto mais controverso sobre o sentido da anistia: a questão da reciprocidade. A existência de dúvidas a respeito de se os torturadores estariam ou não incluídos no espectro de "crimes políticos ou conexos com estes" gera questionamentos até hoje e foi questão matriz da ADPF n ${ }^{\circ} 153$.

$\mathrm{O}$ art. $6^{\circ}$, por sua vez, confere tratamento aos desaparecidos, se limitando a uma a concessão de declaração de ausência aos familiares, por meio de requerimento documentado provando que o parente está desaparecido há mais de um ano.

Art. $6^{\circ} \mathrm{O}$ cônjuge, qualquer parente, ou afim, na linha reta, ou na
colateral, ou o Ministro Público, poderá requerer a declaração de
ausência de pessoa que, envolvida em atividades políticas, esteja,
até a data de vigência desta Lei, desaparecida do seu domicílio, sem
que dela haja notícias por mais de 1 (um) ano
$\S 3^{\circ}$ - Se os documentos apresentados pelo requerente constituirem
prova suficiente do desaparecimento, o juiz, ouvido o Ministério
Público em 24 (vinte e quatro) horas, proferirá, no prazo de 5
(cinco) dias e independentemente de audiência, sentença, da qual,
se concessiva, não caberá recurso.
$\S 4^{\circ}$ - Depois de averbada no registro civil, a sentença que declarar
a ausência gera a presunção de morte do desaparecido, para os fins
de dissolução do casamento e de abertura de sucessão definitiva.

Este artigo é uma das maiores expressões positivadas no sentido de demonstrar a ideia de esquecimento buscada pela lei, que tenta resolver a questão dos mortos e desaparecidos políticos concedendo uma mera declaração de ausência, cujo ônus da prova incumbe aos familiares da vitimas. Com isso, nota-se o descaso com que o governo lidou com a história dos desaparecidos e, no plano físico, o pouco interesse em localizar os corpos, perpetuando, assim, os sentimentos de angustia e esperança naqueles que viram seus entes queridos desaparecerem.

\footnotetext{
${ }^{14}$ BRASIL. Lei $\mathbf{n}^{\mathbf{0}} \mathbf{6 . 6 8 3}$, de 28 de agosto de 1979. Concede anistia e dá outras providências. Disponível em: http://www.planalto.gov.br/ccivil_03/leis/L6683.htm. Acesso em: 03 jul. 2019.

${ }^{15}$ BRASIL. Lei $\mathbf{n}^{\mathbf{0}} \mathbf{6 . 6 8 3}$, de 28 de agosto de 1979. Concede anistia e dá outras providências. Disponível em: http://www.planalto.gov.br/ccivil_03/leis/L6683.htm. Acesso em: 03 jul. 2019.
} 
Atualmente, o debate entorno do tema justiça de transição caminha delicadamente em cima de uma sensível linha tênue dividida entre punir de forma exemplar e esquecer totalmente os crimes cometidos durante o passado autoritário.

Esse debate dicotômico conduz discussões judiciais e acadêmicas sobre justiça de transição desde o final da segunda guerra mundial. E, no Brasil, a respeito da lei de anistia, também se fez presente.

No final do governo Lula ocorreu uma judicialização do processo de transição, por meio de Arguição de Descumprimento de Preceito Fundamental (ADPF) impetrada pelo Conselho Federal da Ordem dos Advogados do Brasil (OAB) no Supremo Tribunal Federal (STF) questionando a validade do artigo $1^{\circ}$ da lei de anistia, com o objetivo de buscar uma interpretação conforme a Constituição no sentido de que "a anistia concedida pela Lei n. 6.683/79 aos crimes políticos ou conexos não se estende aos crimes comuns praticados pelos agentes da repressão, contra opositores políticos, durante o regime militar". ${ }^{16}$ Assim, ao abranger proteção aos agentes que praticaram crimes de homicídio, sequestro, tortura, estupro, desaparecimento e outros, a lei violaria diversos preceitos fundamentais da Constituição de 1988, especialmente o principio fundamental da dignidade da pessoa humana.

Em 2010, a Corte decidiu, por 7 votos a 2, pela improcedência da ADPF $n^{\circ} 153$, rejeitando o pedido da OAB por uma revisão da Lei $n^{\circ}$ 6.683/79, entendendo que não cabe ao Poder Judiciário rever o acordo político feito na transição do regime militar para a democracia e que a anistia aos crimes políticos é, sim, estendida aos crimes "conexos", como diz a lei, e esses crimes são de qualquer ordem.

Pouco mais de 6 meses após a decisão do STF, o Brasil foi condenado, por unanimidade, pela Corte Interamericana de Direitos Humanos (CIDH) em razão de crimes cometidos na Guerrilha do Araguaia, no Caso Gomes Lund e outros vs. Brasil. Para aquela Corte, as disposições da lei da anistia brasileira que impedem a investigação e a sanção a graves violações de direitos humanos são incompatíveis com a Convenção Americana de Direitos Humanos, da qual o país é signatário e não podem permanecer como obstáculo para a investigação dos fatos, nem para a identificação e punição dos responsáveis.

\footnotetext{
${ }^{16}$ BRASIL. Supremo Tribunal Federal. Arguição de Descumprimento de Preceito Fundamental no 153/DF - Distrito Federal. Relator Ministro Luiz Fux, 28 de abril de 2010. Disponível em: http://www.stf.jus.br/portal/jurisprudencia/listarConsolidada.asp?classe=ADI\&numero=3026\&orige m=AP. Acesso em: 24 jun. 2019.
} 
A sentença da CIDH declarou que o Estado brasileiro é responsável pelo desaparecimento forçado e, portanto, pela violação dos direitos ao reconhecimento da personalidade jurídica, à vida, à integridade pessoal e à liberdade pessoal dos guerrilheiros. A corte determinou, nesse sentido, que o Brasil deve conduzir a investigação penal dos fatos, determinar o paradeiro das vítimas e entregar seus restos mortais às famílias, realizar ato público de responsabilidade pelos fatos e indenizar as vítimas ou suas famílias, entre outras disposições.

Defende este estudo que a lei de anistia brasileira contribui para apagar o passado e impedir a construção de uma memória coletiva, pois confunde o não estabelecimento de punições aos agentes estatais perpetradores de violações de direitos com a recusa a investigar a culpa.

Cada povo, de acordo com as suas raízes culturais, lida de forma diferente com o passado produzindo, assim, um efeito diferente do passado no presente e no futuro. Nesse sentido, a questão primordial a ser levada em consideração é se o esquecimento gera harmonia ou tensão e se punição acirra atritos ou produz justiça dentro de cada sociedade.

\section{CONSIDERAÇÕES FINAIS}

Ao longo do presente estudo, pôde-se compreender as nuances do processo de justiça transicional brasileira, sendo possível identificar a dinâmica histórica na qual a transição foi realizada.

Dentro desse complexo processo, a lei de anistia de 1979 marcou o início da justiça de transição no país, se tornando, também, um verdadeiro óbice à responsabilização dos agentes estatais perpetradores de violações de direitos durante a ditadura civil-militar, uma vez que a referida lei estendeu o beneficio da anistia de forma a abranger esses agentes. Os ativistas, contudo, desde o início da campanha, não incluíam a extensão do beneficio aos agentes repressores da ditadura. Pelo contrário, exigiam o esclarecimento sobre mortes e desaparecimentos, bem como a devida punição dos torturadores, com o fim de preservar a verdade e a memória. O regime, por sua vez, defendia uma anistia parcial e recíproca.

Assim, a escolha por uma transição pactuada, baseada na política do esquecimento, não atendeu a demanda de diversos setores da sociedade, em especial das vítimas e familiares das vítimas do regime, contribuindo, assim, para a fomentação de diversos anseios que não foram atendidos até hoje. 
Em 2010, o Supremo Tribunal Federal, em decisão histórica no julgamento da $\mathrm{ADPF} \mathrm{n}^{\circ} 153$, rejeitou o pedido da $\mathrm{OAB}$ por uma revisão da lei de anistia, ratificando a conveniência do Poder Judiciário com a política de esquecimento.

Em face do contexto internacional, o país foi condenado pela Corte Interamericana de Direitos Humanos, que declarou que o Estado brasileiro é, sim, responsável por determinadas violações de direitos ocorridas durante o regime militar.

A partir do conteúdo suscitado, constata-se que o discurso de esquecimento defendido pelos militares desde o início da abertura política foi assimilado por diversos setores da sociedade. Nesse sentido, conclui-se que o debate em torno do tema não deve se restringir a uma visão maniqueísta baseada na perspectiva dicotômica entre esquecimento total e punição exemplar, mas deve-se concentrar no aspecto da construção e preservação da memória, bem como na luta contra o legado autoritário.

\section{REFERÊNCIAS}

ARQUEDIOCESE DE SÃO PAULO. Brasil: nunca mais. 15. ed. Petrópolis: Vozes, 1985.

BARBOSA, Ruy. Amnistia inversa: caso de teratologia jurídica. 2. ed. Rio de Janeiro: Typ. Do Jornal do Commercio, 1986.

BOBBIO, Norberto. A era dos direitos. 9. ed. Tradução de Carlos Nelson Coutinho. Rio de Janeiro: Campus, 1992.

BRASIL. Decreto-lei no 2.848 , de 7 de dezembro de 1940. Código Penal. Disponível em: http://www.planalto.gov.br/ccivil_03/decreto-lei/del2848compilado.htm. Acesso em: 02 jul. 2019.

BRASIL. Lei $n^{\circ} 6.683$, de 28 de agosto de 1979. Concede anistia e dá outras providências. Disponível em: http://www.planalto.gov.br/ccivil_03/leis/L6683.htm. Acesso em: 03 jul. 2019.

BRASIL. Supremo Tribunal Federal. Arguição de Descumprimento de Preceito Fundamental $\mathrm{n}^{\circ}$ 153/DF - Distrito Federal. Relator Ministro Luiz Fux, 28 de abril de 2010. Disponível em: http://www.stf.jus.br/portal/jurisprudencia/listarConsolidada.asp?classe=ADI\&numero=3026\&orige $\mathrm{m}=\mathrm{AP}$. Acesso em: 24 jun. 2019.

GASPARI, Elio. A ditadura derrotada. 2. ed. São Paulo: Companhia das Letras, 2003.

GASPARI, Elio. A ditadura encurralada. 2. ed. São Paulo: Companhia das Letras, 2004.

GASPARI, Elio. A ditadura envergonhada. 2. ed. São Paulo: Companhia das Letras, 2002. 
GASPARI, Elio. A ditadura escancarada. 2. ed. São Paulo: Companhia das Letras, 2002.

MARTINEZ, Pablo Dominguez. Direito ao Esquecimento: a proteção da memória individual na sociedade da informação. Rio de Janeiro: Lumem Juris, 2014.

MEZAROBBA, Glenda. 26 anos de anistia: um processo inconcluso. In: Novos Estudos, $\mathrm{n}^{\circ}$ 70, São Paulo, 2004.

PINHEIRO, Paulo Sérgio. A cidadania das classes populares, seus instrumentos de defesa e o processo constituinte. In: SADER, E. (Org). Constituinte e Democracia no Brasil hoje. 2. ed. São Paulo: Brasiliense, 1985.

PIOVESAN, Flávia. Direitos humanos e o direito constitucional internacional. 7. ed. São Paulo: Saraiva, 2006.

SOUZA, Sávia Cordeiro de. A justiça de transição brasileira: Lei 6.683/79 e a luta contra uma política de esquecimento. 2012. Dissertação (Mestrado em Direito) - Faculdade de Direito da Pontifícia Universidade Católica, Rio de Janeiro, 2012. 